\title{
Evaluation of radiological findings in pediatric patients with COVID-19 in Turkey
}

\author{
(D) Sevinc Kalin, ${ }^{1}$ (1) Saliha Ciraci, ${ }^{1}$ (D) Deniz Cakir, ${ }^{2}$ (D) Aslihan Semiz Oysu, ${ }^{3}$ (D) Betul Sozeri, ${ }^{4}$ \\ Derhat Demir, ${ }^{4}$ (D) Yasar Bukte ${ }^{1}$ \\ ${ }^{1}$ Department of Pediatric Radiology, Health Sciences University, Istanbul Umraniye Training and Research Hospital, Istanbul, Turkey \\ 2Department of Pediatric Infectious Diseases, Health Sciences University, Istanbul Umraniye Training and Research Hospital, Istanbul, Turkey \\ ${ }^{3}$ Department of Radiology, Health Sciences University, Istanbul Umraniye Training and Research Hospital, Istanbul, Turkey \\ ${ }^{4}$ Department of Pediatric Rheumatology, Health Sciences University, Istanbul Umraniye Training and Research Hospital, Istanbul, Turkey
}

\begin{abstract}
OBJECTIVE: The objective of the study was to describe the findings of pediatric patients diagnosed with COVID-19 in computed tomography (CT) and chest X-ray (CXR) images. Therefore, the aim of this study is to show protecting the children from radiation as much as possible while guiding the diagnosis.

METHODS: Between March and June 2020, 148 pediatric patients examined who underwent CT due to suspicion of COVID-19. Fifty patients of 148 with normal thorax CT and negative reverse transcription polymerase chain reaction (RTPCR) were excluded from the study. Of the remaining 98 patients were evaluated retrospectively by two pediatric radiologists with 15 years of experience.

RESULTS: The demographic, clinical, and laboratory data were evaluated for 52 RT-PCR-positive patients. CT finding of 23 RT-PCR positive and 12 negative patients was classified. According to our study, unilateral (61-67\%), multifocal (50-52\%), and peripheral (83-91\%) involvement were higher in all groups. Lower lobe involvement was frequently detected (58-65\%). The most frequently detected parenchymal lesion was ground-glass opacity followed by consolidated areas accompanying ground-grass opacities. Halo sign and vascular enlargement signs were the common signs of lung lesions (35\%). In addition, some rare findings not previously described in this disease in children were mentioned in this study. The clinical course of all our patients was mild and control radiological imaging checked by CXR.

CONCLUSION: Most pediatric patients have a mild course. Hence, a balance between the risk of radiation and necessity for chest CT is very important. Low-dose CT scan is more suitable for pediatric patients but still it should be used cautiously.

Keywords: COVID-19; infectious diseases; pediatric patients; thorax computed tomography.

Cite this article as: Kalin S, Ciraci S, Cakir D, Semiz Oysu A, Sozeri B, Demir F, Bukte Y. Evaluation of radiological findings in pediatric patients with COVID-19 in Turkey. North Clin Istanb 2021;8(4):332-339.
\end{abstract}

T here was no pediatric case report, when the pandemic caused by coronavirus-2 (SARS-CoV-2) began in Wuhan city of China in December 2019. The first pediatric case was reported on January 20 in Shenzhen. Later, with the spread of the virus, it was stated that all age groups were sensitive to the COVID-19 virus and pe- diatric case reports started to be published [1]. However, literature reports on pediatric patients were limited [2,3].

Children are generally more sensitive to some infectious diseases than adults and these infectious diseases have a more fatal course on children. Seasonal influenza may be more mortal than adults in children, especially younger

Received: October 31, 2020 Accepted: December 29, 2020 Online: August 25, 2021

Correspondence: Sevinc KALIN, MD. Saglik Bilimleri Universitesi, Istanbul Umraniye Egitim ve Arastirma Hastanesi, Pediatrik Radyoloji Klinigi, Istanbul, Turkey.

Tel: +90216 6324850 e-mail: svnctsr@yahoo.com

(c) Copyright 2021 by Istanbul Provincial Directorate of Health - Available online at www.northclinist.com 
than 6 months [4]. COVID-19 pandemic and the seasonal winter-spring flu occurring at the same time made early and accurate diagnosis difficult in pediatric pneumonias.

Patients diagnosed with COVID -19 may be clinically asymptomatic or may have a mortal course with a severe pneumonia [5, 6]. In adults, COVID-19 pneumonia has been described in many studies with its typical features in detail [7]. SARS-CoV-2 is less invasive in children than in adults. There are less radiological data due to the lower numbers of child patients and more limited use of computed tomography (CT) in children. To protect children especially from radiation, it is necessary to follow up with radiographs and decide on CT according to the clinical situation [7].

There are many limitations of using reverse transcription polymerase chain reaction (RT-PCR) test at diagnosis of COVID-19, and its sensitivity has been demonstrated in the range of $30-70 \%$. However, the test being negative does not exclude the possibility of COVID-19 [8]. Chest radiographs have low sensitivity (20\%) and are not the first imaging method to be preferred during early period of COVID-19 [9].

Chest CT has become the worldwide accepted imaging method for diagnosis and follow-up in suspected cases of adult patients with COVID-19. Compared to RT-PCR method, the sensitivity, specificity, and accuracy rates of CT were $97 \%, 25 \%$, and $68 \%$. The positive and negative predictive values were around $65 \%$ and $83 \%$, respectively, for CT examination. In addition, we can see $60-93 \%$ positive CT findings before RT-PCR becomes positive [10].

Thorax CT and chest X-ray (CXR) examinations were evaluated in pediatric patients who were admitted to our hospital during the epidemic period and were diagnosed with COVID-19 by their clinical, laboratory, and radiological data. We describe the findings of chest $\mathrm{CT}$ and radiography in pediatric patients diagnosed with COVID-19 to guide the treatment in early diagnosis and clinical follow-up. At the same time, the aim of this study is to emphasize a balance between the risk of radiation and necessity for chest CT.

\section{MATERIALS AND METHODS}

Our study was in a single center, in University of Health Sciences Istanbul Umraniye Training and Research Hospital. This study was approved by our Umraniye Training and Research Hospital Clinical Research Ethics Committee (Number B.10.1.TKH.4.34.H.G.P.0.0.1/221 Date: June 11, 2020).

\section{Highlight key points}

- Similar and different radiological findings have been described in children diagnosed with COVID-19 with lung parenchma involvement. In general, the course of the disease is seen to be milder in children compared to adults. Unfortunately, due to lack of clinical experience in the first mounts of pandemic, a large number of CT examinations were performed especially in adults.

- In this process, we emphasize the choice of radiological examination by looking at reducing the number of radiological examinations and its contribution to the treatment process with our experience in children.

The RT-PCR test used in isolation of SARS-CoV-2 was repeated 3 times for each patient.

Clinical information, laboratory results, and epidemiological data of the patients were reviewed. Between March 15 , and June 1,2020 , pediatric patients (0-18 age) who were referred to the radiology department with suspicion of COVID-19 pneumonia and underwent low-dose chest CT scan were included in the study. Patients with normal chest CT and negative PCR test were excluded from the study. The chest CT images of the pediatric patients with a positive PCR or abnormal chest CT findings were reviewed from the PACS and evaluated retrospectively by two pediatric radiologists with 15 years of experience.

All examinations were carried out using the $128 \mathrm{de}$ tector Optima CT 660 SE (GE Healthcare, Milwaukee, USA) device available in our hospital in accordance with the low-dose CT protocol set for the pediatric patients. The patients were protected from unnecessary radiation using the automatic exposure control system in reference to the thoracic volume.

Tube current exposure time product ( $\mathrm{mAs}$ ) value was in the range of 55-90, and the kilovolt (kv.) value was in the range of 80-100 in reference to the body volume of the patients.

In thorax CT, both lung parenchyma $(-700-+1500$ $\mathrm{HU})$ and mediastinal area $(+50-+350 \mathrm{HU})$ were evaluated. Thorax CT was performed in a supine position without using contrast agent. In patients who could cooperate, the scan was performed at the end of inspiration. Images with adequate quality could not be obtained in some uncooperative patients.

\section{Statistical Analysis}

The Statistical Package for the Social Sciences (SPSS) (version 23.0, SPSS-Inc., Chicago, IL, USA) was used 


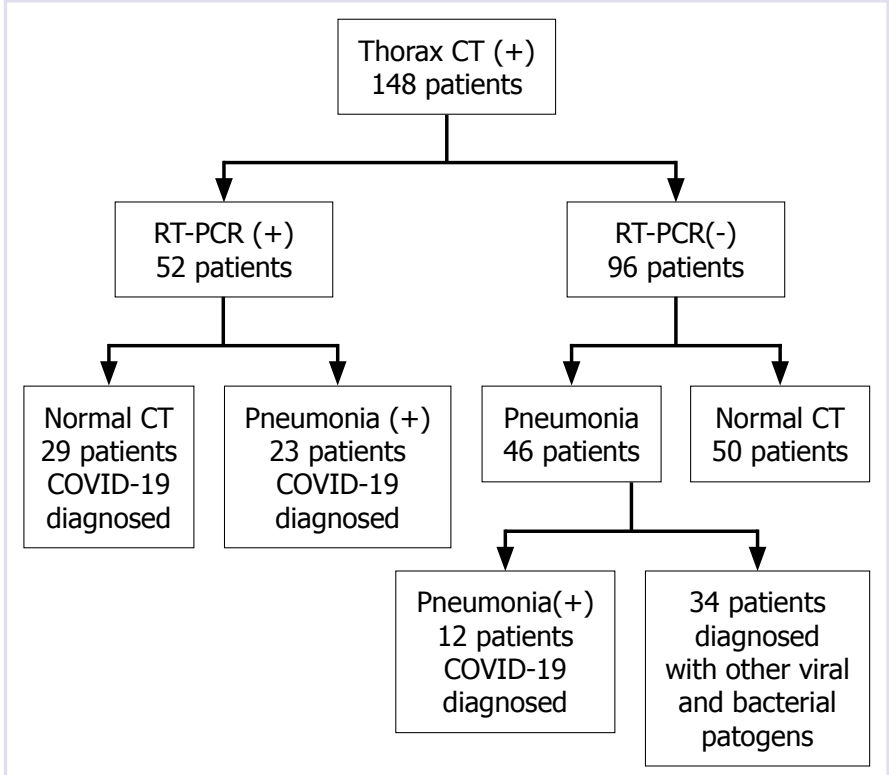

FIGURE 1. Sampling table; classification of pediatric patients with CT examination diagnosed with COVID-19 between March 2020 and June 2020 in University of Health Sciences Istanbul Umraniye Training and Research Hospital.

for statistical analysis. Categorical data were presented as numbers and percentages.

\section{RESULTS}

Chest CT scan was performed in 148 patients $(78$ males and 70 females) with clinical suspicion of COVID-19. Of these, 50 patients with negative RT-PCR tests and also normal CT were excluded from the study.

Forty-six patients with negative RT-PCR tests and abnormal CT finding and 52 patients with positive RTPCR test were included in this study (Fig. 1).

Demographic, clinical, and laboratory data of 52 patients with positive RT-PCR are demonstrated in Figure 1.

In group of 52 patients with positive RT-PCR test, 23 were male (44.2\%), 29 were female (55.8\%), and the median age was $13.37( \pm 4.8)$. The patients are categorized in five groups (Table 1). Most patients were in the group older than 15 years of age (42.3\%). There were 40 patients with contact history $(76.9 \%)$. The most common symptoms are cough (57.7\%), respiratory distress (42.3\%), and fever $(21.2 \%)$. Comorbid disease was observed in 8 patients $(15.4 \%)$ and hospitalization was required in 33 (63.5\%) patients. Most of our patients had a mild course and completely healed. Pediatric multisystem inflammatory syndrome was observed in two of our patients.
TABLE 1. Dermographic, clinical, and laboratory data of 52 PCR-positive patients

\begin{tabular}{|c|c|}
\hline Characteristics & Number $(n=52) \%$ \\
\hline \multicolumn{2}{|l|}{ Sex } \\
\hline Boy & 44.2 \\
\hline Girl & 55.8 \\
\hline \multicolumn{2}{|l|}{ Age } \\
\hline$<1$ year & 1.9 \\
\hline $1-5$ years & 9.6 \\
\hline $6-10$ years & 17.3 \\
\hline $11-15$ years & 26.9 \\
\hline$>15$ years & 44.2 \\
\hline \multicolumn{2}{|l|}{ Contact history } \\
\hline Yes & 76.9 \\
\hline Uncertainty & 23.1 \\
\hline \multicolumn{2}{|l|}{ Symptoms } \\
\hline Cough & 57.7 \\
\hline Respiratory distress & 42.3 \\
\hline Fever & 21.2 \\
\hline Sore throat & 15.4 \\
\hline GIS symptoms & 13.5 \\
\hline Joint findings & 11.5 \\
\hline Headache & 9.6 \\
\hline Fatigue & 5.8 \\
\hline Loss of taste and smell & 3.8 \\
\hline Comorbid disease & 15.4 \\
\hline Hospitalization & 63.5 \\
\hline \multicolumn{2}{|l|}{ Abnormal laboratory findings } \\
\hline Leukocytosis & 9.6 \\
\hline Lymphopenia & 25 \\
\hline CRP $<0.5$ & 76.9 \\
\hline $\mathrm{CRP}>0.5$ & 23.1 \\
\hline Procalcitonin $<0.05 \mathrm{ng} / \mathrm{ml}$ & 94.2 \\
\hline$>0.05 \mathrm{ng} / \mathrm{ml}$ & 5.8 \\
\hline
\end{tabular}

PCR: Polymerase chain reaction; CRP: C-reactive protein.

While leukocytosis was found in 5 patients (9.6\%), lymphopenia was noted in 13 patients (25\%). C-reactive protein (CRP) values were normal in $76 \%$ of patients and procalcitonin was $<0.05 \mathrm{ng} / \mathrm{ml}$ in $94 \%$ of patients.

In CT examination, there were no findings compatible with pneumonia in $29(55.8 \%)$ of 52 patients with positive RT-PCR tests. In those 29 patients, CT findings were normal.

In the RT-PCR-positive group, 23 of 52 (Group 1) patients had $C T$ examinations compatible with COVID-19 pneumonia. 
TABLE 2. Radiological findings in patients diagnosed with COVID-19 pneumonia. We described CT findings in two group. Group 1 patients had positive RT-PCR tests and pneumonia findings. Group 2 patients had negative RT-PCR tests and pneumonia findings

\begin{tabular}{|c|c|c|}
\hline Thorax CT findings & $\begin{array}{c}\text { First } \\
\text { group } \\
(\mathrm{n}=23) \\
\text { RT-PCR (+) } \\
\text { patients, \% }\end{array}$ & $\begin{array}{c}\text { Second } \\
\text { group } \\
(\mathrm{n}=12) \\
\text { RT-PCR (-) } \\
\text { patients, \% }\end{array}$ \\
\hline \multicolumn{3}{|l|}{ Distributions of lesions } \\
\hline Unilateral/bilateral & $60.9 / 39.1$ & $66.7 / 33.3$ \\
\hline Unilobar/multilobar & $43.5 / 56.5$ & $58.3 / 45.7$ \\
\hline Peripheral/peripheral+central & $91.3 / 8.7$ & $83.3 / 16.7$ \\
\hline Multifocal/unifocal & $52.2 / 47.8$ & $50 / 50$ \\
\hline Diffuse & 0 & 8.3 \\
\hline Upper lobes & 52.2 & 66.7 \\
\hline Middle lobes & 21.7 & 25 \\
\hline Lower lobes & 65.2 & 58.3 \\
\hline \multicolumn{3}{|l|}{ CT appearances of lesions } \\
\hline GGO & 60.9 & 50 \\
\hline GGO+consolidation & 26.1 & 50 \\
\hline Consolidation & 13 & 0 \\
\hline Mosaic attenuation & 8.7 & 25 \\
\hline \multicolumn{3}{|l|}{ CT signs } \\
\hline Halo sign & 34.8 & 16.7 \\
\hline Vascular enlargement & 34.8 & 8.3 \\
\hline Nodule & 8.7 & 16.7 \\
\hline Peribronchial thickening & 8.7 & 0 \\
\hline Reversed halo sign & 4.3 & 0 \\
\hline Tree in bud & 0 & 8.3 \\
\hline \multicolumn{3}{|l|}{ Extrapulmonary findings } \\
\hline Pleural effusion & 4.3 & 0 \\
\hline Pleural thickening & 8.7 & 8.3 \\
\hline Mediastinal lymph node & 4.3 & 0 \\
\hline
\end{tabular}

RT-PCR: Reverse transcription polymerase chain reaction; CT: Computed tomography; GGO: Ground-glass opacity.

In the group with negative RT-PCR test and CT findings consistent with pneumonia, 12 of 46 (Group 2) were diagnosed with COVID-19 by clinical observation and follow-up. The remaining 34 of 46 patients were diagnosed with other diseases during clinical and laboratory follow-up (other viral factors, bacterial pneumonia, aspiration pneumonia, etc.).

Thorax CTs were classified according to the distribution of lesions and their appearance in CT (Table 2).
TABLE 3. Evaluation of CXR findings of PCR positive 23 patients with pneumonia in $\mathrm{CT}$

\begin{tabular}{ccc} 
Normal & Abnormal & Total \\
CXR, \% & CXR, \% & \\
\hline
\end{tabular}

\begin{tabular}{llll}
\hline CT (pneumonia, etc.) & 82.7 & 17.3 & $23(100 \%)$ \\
\hline
\end{tabular}

CXR: Chest X-ray; PCR: Polymerase chain reaction; CT: Computed tomography.
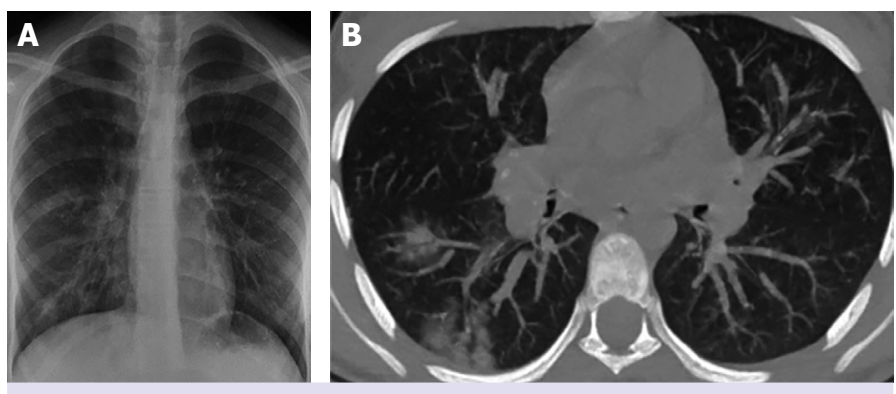

FIGURE 2. (A) A 13-year-old girl with COVID-19 (RT-PCR positive). Chest $\mathrm{X}$-ray shows multifocal opacities at lower zone of the right lobe, (B) non-contrast CT scan shows unilateral multicentric consolidation with peripheral groundglass opacities (halo sign). Most of lesions are peripherally located in lower lobe.

There was no need to repeat CT in patients who were diagnosed with COVID-19. Clinically, the patients had a mild course and followed up by CXR.

Direct radiographs of Group 1 patients were evaluated. Only 4 (17.3\%) of these patients had signs of pneumonia by CXR (Fig. 2A). Although there were signs of pneumonia in CT in the remaining 19 (82.7\%) patients, CXRs were completely normal (Table 3 ).

\section{CT Appearances and CT Signs}

\section{Ground-glass opacity (GGO)}

Hazy hyperattenuated areas are typically caused by partial filling of air spaces by exudate or transudates without obstruction of the underlying vessels (Fig. 2B, 3A, B). It is the earliest manifestation and may be with or without other CT findings. It is the most common CT finding, seen in up to $86.1 \%$ of our patients.

\section{Halo sign}

Halo sign is a CT finding of ground-glass opacity surrounding a nodule or mass. It has been demonstrated in a variety of diseases, including the angioinvasive fungal infections, viral infections, organizing 

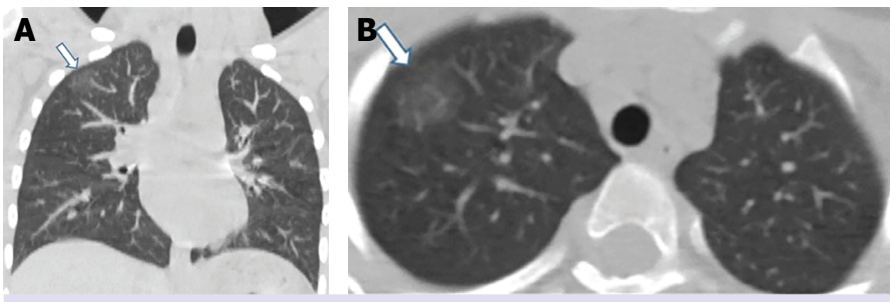

FIGURE 3. (A, B) A 9-year-old boy with respiratory distress and fever diagnosed COVID-19 clinically but RT-PCR-negative patient. Chest X-ray was normal. Coronal (A) and axial (B) non-contrast CT images show unilateral peripheral ground-grass opacity.
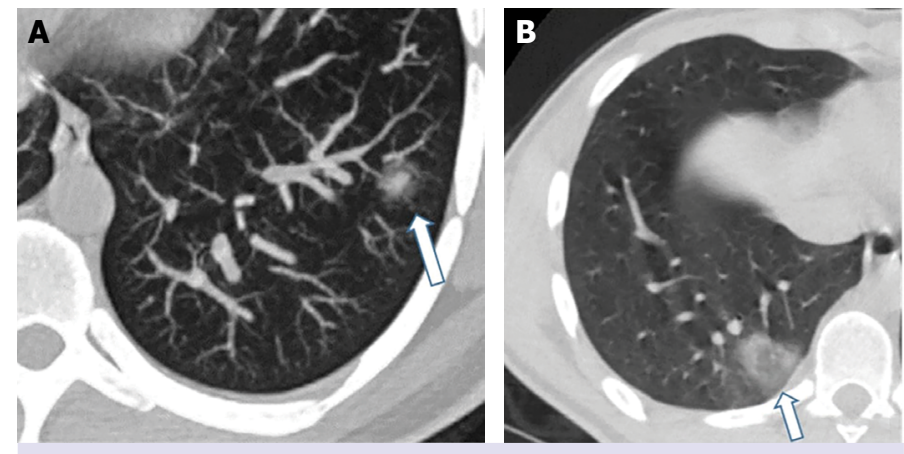

FIGURE 4. (A) A 17-year-old boy with COVID-19 (RT-PCR positive). Non-contrast CT scan shows halo sign, (B) a 16-year-old boy with COVID-19 (RT-PCR positive). Non-contrast CT scan shows reversed halo sign.

pneumonia, and hypervascular metastases. In our study, halo sign was presented in about $35 \%$ of patients (Fig. 4A).

\section{Reversed halo sign}

Reversed halo sign defines a focal round GGO surrounded by complete or incomplete ring-like consolidation (Fig. 4B). It used to be a pathognomonic CT finding for cryptogenic organizing pneumonia. Later, it was described in many diseases. In our pediatric COVID-19 group, reversed halo sign finding was present in only 1 patient $(4.3 \%)$.

\section{Consolidation}

Filling of the alveolar air spaces completely. As a result, we see hyperattenuated area with obscuration of underlying vessels (Fig. 5A). Multifocal and peripheral consolidations were present in COVID-19 pneumonia. In our patients, consolidation was the second most common CT finding seen in up to $39.1 \%$.

\section{Peribronchial thickening}

To describe haziness or increased density around
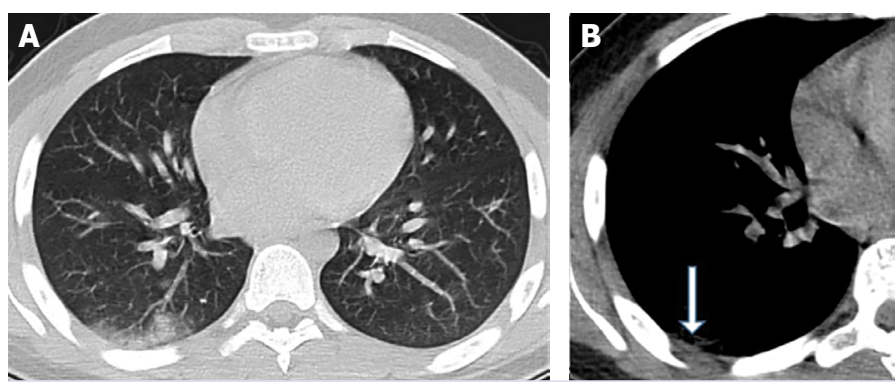

FIGURE 5. (A, B) A 14-year-old boy with cough and diagnosed COVID-19 (RT-PCR positive). Non-contrast CT scan shows peripheral consolidations with vascular enlargement (A) and pleural thickening (B).
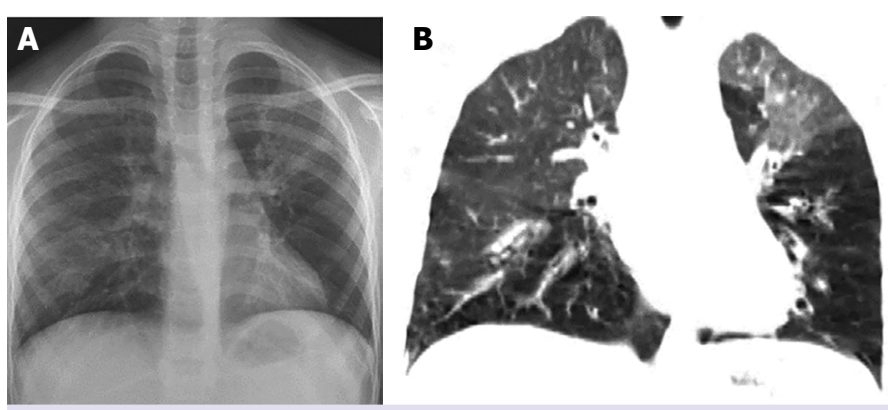

FIGURE 6. (A, B) An 8-year-old girl with fever diagnosed COVID-19 (RT-PCR positive). We see bilateral diffuse opacities at chest X-ray. Non-contrast CT scan shows mosaic attenuation created by ground-glass opacity and air trapping areas.

the walls of a bronchus or large bronchiole seen both on plain radiographs and on CT. It is present in only 2 patients $(8.7 \%)$ in our study (Fig. 5A).

\section{Vascular enlargement}

Dilatation of pulmonary vessels within the lesions, especially in GGO (Fig. 5A). It was a quite common sign in our study $(35 \%)$.

Pleural thickening: Normal pleura is thinner than 1 $\mathrm{mm}$. In the course of lung diseases, thickening may be accompanied by recurrent infections. This finding was present in only 2 patients (8.7\%) in our study (Fig. 5B).

\section{Mosaic attenuation}

It refers to areas of decreased attenuation secondary to airway disease or pulmonary vascular disease which results from regional differences in lung perfusion. It was a rare CT finding at $2-3 \%$ (Fig. $6 \mathrm{~A}, \mathrm{~B}$ ).

\section{Nodule}

In our study, this finding was defined in 2 patients $(8.7 \%)$. 
According to our CT examination in patients diagnosed with COVID-19, unilateral involvement was higher in both groups $(60.9 \%$ in Group 1 and $66.7 \%$ in Group 2). When we evaluated Table 1, multilobar involvement was observed more frequently in Group 1, whereas unilobar involvement was relatively higher in Group 2. In both groups, multifocal and unifocal involvements were observed in approximately the same rate. The majority of the patients had disease involvement in the peripheral lung areas $\left(1^{\text {st }}\right.$ group $91 \%$ and $2^{\text {nd }}$ group $\left.83 \%\right)$. Lower lobes were relatively more affected by the disease.

In both groups, GGO (about 50\%) is the most common appearance of the lesions in COVID-19. Second, consolidated areas accompanying ground-grass opacities were defined. The mosaic attenuation appearance was a less common finding and detected in three patients in our study (8.7\% in Group 1and 25\% in Group 2).

Halo sign and vascular enlargement findings were the most common signs of the disease in lungs. In total, one patient had reversed halo sign and one patient had a tree in bud view.

\section{DISCUSSION}

The number of patients diagnosed with COVID-19 at a pediatric age is much lower than in adults. Furthermore, we still have less CT data than adults because of the limited CT examination to protect pediatric patients from radiation. This study was conducted with the data of our center, which has a large potential for pediatric patients in the Anatolian side of Istanbul.

In the early days of the pandemic, more patients were evaluated by CT due to the lack of clinical experience and panic behavior of their relatives. Afterward, the number of CT scans decreased as clinical experience increased so patients were followed up with CXR. When we examined the demographic, clinical, and laboratory data of 52 patients with positive RT-PCR test, we found that the most affected age group was between 11 and 17. Similar to the literature, most of our patients had a history of contact with a patient diagnosed with COVID-19. Clinical symptoms were presented in all of our patients and mostly we encountered cough, respiratory distress, and fever as in adults $[5-7,11]$.

According to the age groups, hospitalization rate was $80 \%$ in children under 11 years and $56 \%$ in children between 11 and 17 years old. Younger group of patients with comorbid disease was hospitalized longer than the older group. None of our patients needed intensive care. Similarly, in a study conducted by Dong et al. [11] It was reported that the clinical course was more severe in children under 1 year of age which had comorbid disease.

When the laboratory data were examined, it was defined that leukocyte counts were normal in the patients $(\sim 90 \%)$ as stated in the literature, but approximately $25 \%$ of patients developed lymphopenia. Hospitalization period was longer in patients with lymphopenia compared to other groups. CRP values were observed to be normal in approximately $77 \%$ of patients and procalcitonin was normal in almost all except three patients $(<0.05 \mathrm{ng} / \mathrm{ml})$. High procalcitonin may be a precursor of a secondary bacterial infection $[5,6,12]$.

In this study, the clinical course was much milder in children diagnosed with COVID-19 compared to adults. CT was completely normal in 29 of 52 pediatric patients whose PCR test was positive. In the study of Steinberger et al. [13] with 30 pediatric patients, CT examination of 23 patients (77\%) with COVID-19 was considered normal.

In most of our pediatric patients with positive CT compatible with pneumonia, GGO, which was one of the typical findings defined for the disease, was observed. In most of the children with the findings of consolidation, which was the second most frequently observed, consolidations were accompanied by ground-glass opacities. This created the appearance of halo sign, which was one of the signs we frequently saw [14-16].

GGO was one of the most common CT findings and had been described in the literature in $80-98 \%$ of adult and pediatric patients [14, 17-19]. GGO was also one of the earliest manifestations of the disease [20]. It may or may not be accompanied by other findings, such as particularly consolidation and reticulation [21]. While $69 \%$ of our patients only had GGO, $26 \%$ of them had consolidations with GGO.

Mosaic attenuation appearance was defined only in two of our patients and diffused all over the lung (8.7\%). In these patients, clinical findings were more severe and length of hospitalization was longer than other patients (Fig. 5). This sign for COVID-19 was not defined in the literature.

We defined vascular enlargement which was a relatively more specific sign in our pediatric patient group (around 35\%). In the literature, it was stated that approximately $71.3-82.4 \%$ of adult COVID-19 patients had vascular enlargement $[2,22]$. 
Thickened interlobular septa and intralobular lines which appeared as linear opacities on CT were defined as reticulation. Thickened interlobular septa or intralobular lines superimposed on GGO were defined as crazy-paving pattern. It was reported in $5-36 \%$ of patients with COVID-19 pneumonia [20, 23, 24]. Reticulation and crazy-paving pattern were common findings in adult age group in COVID-19 [2, 24-26]. In our study, we did not see neither of those findings. Reticulation was a relatively late finding compared to GGO and consolidation [27]. In our study, all patients were affected mildly and showed rapid recovery.

According to the distribution of the lesions, unilateral involvement was defined more frequently in our pediatric patients, albeit with a slight difference. In the literature, bilateral lung involvement was mentioned more frequently in both pediatric age groups and adults. Unilateral involvement observed in both our study groups may be due to early diagnosis. In most of our patients, we defined multicentric peripheral lesions in lower lobes similar to the literature $[15,27]$.

Extrapulmonary lesions were rarely detected in this study as recorded in literature. Secondary bacterial infections may have been present in these patients.

CXR may be used in COVID-19 pneumonia as the first imaging modality compared to CT with the advantages of less ionizing radiation. It has many advantages due to it being portable and its ease of sterilization.

CXR of Group 1 was evaluated. Only four of these 23 patient's pneumonia could be detected in CXR. Although there were signs of pneumonia in CT in 19 $(82.7 \%)$ patients, CXRs were completely normal (Table 3). Accordingly, the sensitivity of CXR was very low with $17 \%$ in this study. The sensitivity of CXR was not remarkably higher than the R-PCR test, ranges between $33 \%$ and $69 \%$ [28].

CXR may be useful in the diagnosis of other disease such as lobar pneumonia due to bacterial infections, pulmonary edema, pneumothorax, and pleural effusion that may mimic COVID-19 pneumonia. CXR may be helpful to evaluate the progression of diseases in hospitalized patients [29]. In the presence of high clinical suspicion and normal radiography, CT may be employed to detect diseases for a timely isolation and treatment of patients due to its sensitivity for early pneumonic changes [30]. CT appears to have a higher sensitivity than RT-PCR test reported that CT sensitivity was $97.2 \%$, while RTPCR test sensitivity was $83.3 \%$ [31]. CT may detect
COVID-19 pneumonia in asymptomatic patients [32]. Despite its relatively high sensitivity, it is recommended to confirm the diagnosis of clinically suspected patients if the RT-PCR test is negative or unavailable, for to isolate and treat the patients quickly $[33,34]$.

\section{Limitations in Our Study}

We limited our CT numbers to protect children from radiation and not enough quality CT images could be obtained in uncooperated patients.

\section{Conclusion}

Chest CT can demonstrate characteristic changes of multifocal, peripheral ground-glass opacities and consolidations with surrounding halo. When some chest CT characteristics of children with COVID-19 were atypical compared to adults, we found localized unilateral involvement, relatively rare interlobular septal thickening, and rare crazy-paving pattern.

Most pediatric patients have a mild course. Hence, a balance between the risk of radiation and necessity for chest CT is very important. Low-dose CT scan is more suitable for pediatric patients but still it should be used cautiously.

Ethics Committee Approval: The University of Health Sciences Istanbul Umraniye Training and Research Hospital Clinical Research Ethics Committee granted approval for this study (date: 11.06.2020, number: B.10.1.TKH.4.34.H.G.P.0.0.1/221).

Conflict of Interest: No conflict of interest was declared by the authors.

Financial Disclosure: The authors declared that this study has received no financial support.

Authorship Contributions: Concept - SK; Design - SK, BS; Supervision - ASO; Materials - ASO, SK; Data collection and/or processing - SK, DC; Analysis and/or interpretation - SK, FD; Literature review - SK, SC; Writing - SK, SC; Critical review - YB, BS.

\section{REFERENCES}

1. Chan JF, Yuan S, Kok KH, To KK, Chu H, Yang J, et al. A familial cluster of pneumonia associated with the 2019 novel coronavirus indicating person-to-person transmission: a study of a family cluster. Lancet 2020;395:514-23. [CrossRef]

2. Fang F, Luo XP. Facing the pandemic of 2019 novel coronavirus infections: the pediatric perspectives. [Article in Chinese]. Zhonghua $\mathrm{Er} \mathrm{Ke}$ Za Zhi 2020;58:81-5.

3. Lin TY, Kao HT, Hsieh SH, Huang YC, Chiu CH, Chou YH, et al. Neonatal enterovirus infections: emphasis on risk factors of severe and fatal infections. Pediatr Infect Dis J 2003;22:889-94. [CrossRef]

4. Chen N, Zhou M, Dong X, Qu J, Gong F, Han Y, et al. Epidemiological 
and clinical characteristics of 99 cases of 2019 novel coronavirus pneumonia in Wuhan, China: a descriptive study. Lancet 2020;395:507-13.

5. Huang C, Wang Y, Li X, Ren L, Zhao J, Hu Yet al. Clinical features of patients infected with 2019 novel coronavirus in Wuhan, China. Lancet 2020;395:497-506. [CrossRef]

6. Wang D, Hu B, Hu C, Zhu F, Liu X, Zhang J, et al. Clinical characteristics of 138 hospitalized patients with 2019 novel coronavirus-infected pneumonia in Wuhan, China. JAMA 2020;323:1061-9. [CrossRef]

7. Kanne JP, Little BP, Chung JH, Elicker BM, Ketai LH. Essentials for radiologists on COVID-19: an update-radiology scientific expert panel. Radiology 2020;296:E113-4. [CrossRef]

8. Choi H, Qi X, Yoon SH, Park SJ, Lee KH, Kim JY, et al. Extension of coronavirus disease 2019 (COVID-19) on chest CT and implications for chest radiograph interpretation. Radiol Cardiothorac Imaging 2020;2:e200107. [CrossRef]

9. Ai T, Yang Z, Hou H, Zhan C, Chen C, Lv W, et al. Correlation of chest CT and RT-PCR testing for coronavirus disease 2019 (COVID-19) in China: a report of 1014 cases. Radiology 2020;296:E32-40. [CrossRef]

10. Lu X, Zhang L, Du H, Zhang J, Li YY, Qu J, et al; Chinese Pediatric Novel Coronavirus Study Team. SARS-CoV-2 infection in children. N Engl J Med 2020;382:1663-5. [CrossRef]

11. Dong Y, Mo X, Hu Y, Qi X, Jiang F, Jiang Z, et al. Epidemiology of COVID-19 among children in China. Pediatrics 2020;145:e20200702.

12. Chen ZM, Fu JF, Shu Q, Chen YH, Hua CZ, Li FB, et al. Diagnosis and treatment recommendations for pediatric respiratory infection caused by the 2019 novel coronavirus. World J Pediatr 2020;16:240-6.

13. Steinberger S, Lin B, Bernheim A, Chung M, Gao Y, Xie Z, et al. CT features of coronavirus disease (COVID-19) in 30 pediatric patients. AJR Am J Roentgenol 2020;215:1303-11. [CrossRef]

14. Chen A, Huang JX, Liao Y, Liu Z, Chen D, Yang C, et al. Differences in clinical and imaging presentation of pediatric patients with COVID-19 in comparison with adults. Radiol Cardiothorac Imaging 2020;2:e200117. [CrossRef]

15. Xia W, Shao J, Guo Y, Peng X, Li Z, Hu D. Clinical and CT features in pediatric patients with COVID-19 infection: Different points from adults. Pediatr Pulmonol 2020;55:1169-74. [CrossRef]

16. Çinkooğlu A, Hepdurgun C, Bayraktaroğlu S, Ceylan N, Savaş R. CT imaging features of COVID-19 pneumonia: initial experience from Turkey. Diagn Interv Radiol 2020;26:308-14. [CrossRef]

17. Li K, Wu J, Wu F, Guo D, Chen L, Fang Z, et al. The clinical and chest CT features associated with severe and critical COVID-19 pneumonia. Invest Radiol 2020;55:327-31. [CrossRef]

18. Hamer OW, Salzberger B, Gebauer J, Stroszczynski C, Pfeifer M. CT morphology of COVID-19: Case report and review of literature. Rofo 2020;192:386-92. [CrossRef]

19. Chung M, Bernheim A, Mei X, Zhang N, Huang M, Zeng X, et al. CT imaging features of 2019 novel coronavirus (2019-nCoV). Radiology
2020;295:202-7. [CrossRef]

20. Song F, Shi N, Shan F, Zhang Z, Shen J, Lu H, et al. Emerging 2019 novel coronavirus (2019-nCoV) pneumonia. Radiology 2020;295:210-7.

21. Li Y, Xia L. Coronavirus disease 2019 (COVID-19): role of chest CT in diagnosis and management. AJR Am J Roentgenol 2020;214:12806. [CrossRef]

22. Bernheim A, Mei X, Huang M, Yang Y, Fayad ZA, Zhang N, et al. Chest CT findings in coronavirus disease-19 (COVID-19): relationship to duration of infection. Radiology 2020;295:200463. [CrossRef]

23. Wu J, Wu X, Zeng W, Guo D, Fang Z, Chen L, et al. Chest CT findings in patients with coronavirus disease 2019 and its relationship with clinical features. Invest Radiol 2020;55:257-61. [CrossRef]

24. Pan F, Ye T, Sun P, Gui S, Liang B, Li L, et al. Time course of lung changes at chest CT during recovery from coronavirus disease 2019 (COVID-19). Radiology 2020;295:715-21. [CrossRef]

25. Hansell DM, Bankier AA, MacMahon H, McLoud TC, Müller NL, Remy J. Fleischner Society: glossary of terms for thoracic imaging. Radiology 2008;246:697-722. [CrossRef]

26. Shi H, Han X, Jiang N, Cao Y, Alwalid O, Gu J, et al. Radiological findings from 81 patients with COVID-19 pneumonia in Wuhan, China: a descriptive study. Lancet Infect Dis 2020;20:425-34. [CrossRef]

27. Yoon SH, Lee KH, Kim JY, Lee YK, Ko H, Kim KH, et al. Chest radiographic and CT findings of the 2019 novel coronavirus disease (COVID-19): analysis of nine patients treated in Korea. Korean J Radiol 2020;21:494-500. [CrossRef]

28. Rubin GD, Ryerson CJ, Haramati LB, Sverzellati N, Kanne JP, Raoof $\mathrm{S}$, et al. The role of chest imaging in patient management during the COVID-19 pandemic: a multinational consensus statement from the fleischner society. Radiology 2020;296:172-80. [CrossRef]

29. Inui S, Fujikawa A, Jitsu M, Kunishima N, Watanabe S, Suzuki Y, et al. Chest CT findings in cases from the cruise ship Diamond Princess with coronavirus disease (COVID-19). Radiol Cardiothorac Imaging 2020;2:e200110. [CrossRef]

30. Long C, Xu H, Shen Q, Zhang X, Fan B, Wang C, et al. Diagnosis of the coronavirus disease (COVID-19): rRT-PCR or CT? Eur J Radiol 2020;126:108961. [CrossRef]

31. Lee EYP, Ng MY, Khong PL. COVID-19 pneumonia: what has CT taught us? Lancet Infect Dis 2020;20:384-5. [CrossRef]

32. Simpson S, Kay FU, Abbara S, Bhalla S, Chung JH, Chung M, et al. Radiological Society of North America Expert Consensus Document on Reporting Chest CT Findings Related to COVID-19: Endorsed by the Society of Thoracic Radiology, the American College of Radiology, and RSNA. Radiol Cardiothorac Imaging 2020;2:e200152. [CrossRef]

33. Xie X, Zhong Z, Zhao W, Zheng C, Wang F, Liu J. Chest CT for typical coronavirus disease 2019 (COVID-19) pneumonia: relationship to negative RT-PCR testing. Radiology 2020;296:E41-5. [CrossRef] 